\title{
Nomophobia and Digital Natives
}

\author{
Jacopo Bernardini
}

In recent years, media attention has been increasingly focused on certain concepts that are closely related to the improper and excessive use of mobile phones: smartphone psychological dependence, the correlation between youth apathy and the massive use of new technologies, and the drastic change of social interaction in the Internet Age. Such phenomena may be considered as the reason behind the emergence of a new contemporary pathology that already has a name: nomophobia. This is a pathology that seems to be quite common at present, particularly in those countries with high levels of smartphone ownership, usage, and penetration, such as Italy. This preliminary field research study begins to map its significance among Italian consumers who are smartphone users.

\section{The Mobile Phone Addiction}

The term nomophobia is an abbreviation for "no mobile phone phobia," and describes the fear of being out of cellular phone contact (D'Agata, 2008). More specifically, it is an irrational and persistent fear of not being able to be connected to the Internet via smartphone. Stewart Fox-Mills coined the term in 2008, while presenting the results of a survey on the use of cellular telephones by British citizens. His research was commissioned by the UK Post Office to the center of online research YouGov (D’Agata, 2008; Colleen, 2008; Jayakumar, 2008).

According to that research, approximately $53 \%$ of Britons suffer from this phobia, particularly young males. Similar results can be found in a survey carried out in the United States by Harris Interactive in 2012. Although the term nomophobia is never mentioned, this survey shows that $63 \%$ of respondents declared conditions of discomfort in the case of going long periods of time without access to mobile phones. Successive research studies have designated the main indicators and symptoms related to this psychopathological manifestation (Bivin, Preeti, Praveen \& Jinto, 2013; King et al., 2014).

The factors identified as typical of a nomophobic subject include the habit of keeping the phone turned on all day, the tendency to feel uncomfortable without one's phone, and frequently posting online news about oneself and one's own experiences, as well as numerous indicators related to how often one checks one's phone and uses certain applications, as well as the frequency of receiving and making calls, messages or notifications. The main symptoms are anxiety, panic, depression, sweating, tremors, tachycardia, abnormal breathing, and feelings of fear. As observed in both studies mentioned above, this phobia is more frequently found in male subjects. However, what seems to be lacking in all existing studies is some sort of reference to the age variable, which this researcher considers fundamental. Articulating such a reference appears to require another notion: the digital generation, as it affixes a chronological context to digital nativity.

Marc Prensky was the first to speak of digital nativity $(2001 ; 2012)$ revolving on two fundamental assumptions: the perception of the individual varies according to the social context in which he is inserted; and the human brain physically mutates depending on one's surroundings. Those generations that have grown through media digitization, Internet evolution, and the diffusion of mobile phones have therefore developed an unprecedented inclination towards technology, attributing values and meanings to it that are often inconceivable for previous generations (Cristofori, Bernardini \& Massarini, 2015). The digital native label is a perfect fit for contemporary youth - born in a near-saturated technologized social scenario and therefore completely at ease within it. The value they confer to 
technological instruments has no precedent; the potential predisposition to nomophobic behaviors is conceivable as being much greater than in the immediately preceding generations. In fact, the digital generation itself has recently been divided into two broad groups: the pure ones - roughly, those born in the mid-Nineties - and the spurious ones - those born in the Eighties and early Nineties (Ferri 2011; 2013; Allega 2013). Only pure digital natives have had an early and direct experience of a pervasive digital context, and are considered to be the main users and connoisseurs of new technology. Also, pure digital natives are those that are more dependent on it.

\section{Survey Methodology}

The population of the study comprised young Italians aged between 18 and 36. Italy has been chosen since it is one of the countries with the highest levels of smartphone and mobile device usage: $128 \%$ mobile subscriptions compared to the national population (global average is 109\%); $51 \%$ active accounts on the top social network accessed via mobile devices, compared to the national population (global average is 39\%); $83 \%$ unique mobile users (global average is 68\%); and 80\% of mobile connections that are broadband (global average is 60\%) (Kemp, 2018).

Stratified sampling has been adopted; the strata were gender and age group. A sample of 200 cases made up the sample for the study: 50 males aged between 18 and 24 and 50 females aged between 18 and 24 (which will be called young adults or pure digital natives); 50 males aged between 25 and 36 and 50 females aged between 25 and 36 (which will be called early adults or spurious digital natives). The questionnaire - composed of 21 multiplechoice questions and 1 open-ended question - was sent via email in January 2015.

The collected data was inserted into a matrix and processed with SPSS 14.0. All variables have been crosschecked by gender and age group. No significant gender differences have been noticed; therefore, only age group cross tabulations will be shown and discussed.

\section{The Results of the Survey}

After the socio-demographic questions, the questionnaire asked how often during the course of an hour the participant checked his/her smartphone, on average, without receiving notifications. Possible answers were: never (selected by $9.5 \%$ of the sample); once (35\%); two or three times (34\%); and more than three times (21.5\%). By comparing these answers with the age group, an initial significant fact emerges: as age increases, so does the frequency with which one controls one's phone. In fact, as can be seen in Table 1, just $6 \%$ of young adults aged between 18 and 24 years old - that is, the pure digital natives - claimed to never check their phones over the course of an hour compared to $13 \%$ of those aged between 25 and 36, the spurious digital natives. This trend is almost perfectly reversed with regard to controlling the smartphone more than three times in an hour.

Table 1. Checking one's smartphone over the course of an hour

\begin{tabular}{|l|c|c|c|}
\hline \multirow{2}{*}{} & \multicolumn{2}{|c|}{ Age } & Total \\
\cline { 2 - 4 } & $\begin{array}{c}\text { Pure Natives } \\
(\mathbf{1 8 - 2 4 )}\end{array}$ & $\begin{array}{c}\text { Spurious Natives } \\
(\mathbf{2 5 - 3 6 )}\end{array}$ & $9.5 \%$ \\
\hline Never & $6.0 \%$ & $13.0 \%$ & $35.0 \%$ \\
\hline Once & $29.0 \%$ & $41.0 \%$ & $34.0 \%$ \\
\hline 2-3 Times & $37.0 \%$ & $31.0 \%$ & $21.5 \%$ \\
\hline More than 3 times & $28.0 \%$ & $15.0 \%$ & $100.0 \%$ \\
\hline Total & $100.0 \%$ & $100.0 \%$ & \\
\hline
\end{tabular}

Note: Column percentage. Age group cross tabulation. $\mathrm{N}=200$

The following question brought similar results: when asked how many times over half an hour each participant 
received an audio notification on the smartphone, most of the pure digital natives answered "twice or more," while early adults mainly answered “once or never" (Table 2).

Table 2. Audio notifications received over the course of half an hour

\begin{tabular}{|l|c|c|c|}
\hline & \multicolumn{2}{|c|}{ Age } & \multirow{2}{*}{ Total } \\
\cline { 2 - 4 } & $\begin{array}{c}\text { Pure Natives } \\
(\mathbf{1 8 - 2 4})\end{array}$ & $\begin{array}{c}\text { Spurious Natives } \\
(\mathbf{2 5 - 3 6 )}\end{array}$ & $44.0 \%$ \\
\hline One/no notification & $42.0 \%$ & $46.0 \%$ & $33.0 \%$ \\
\hline 2-3 notifications & $32.0 \%$ & $34.0 \%$ & $23.0 \%$ \\
\hline More than 3 notifications & $26.0 \%$ & $20.0 \%$ & $100.0 \%$ \\
\hline Total & $100.0 \%$ & $100.0 \%$ & \\
\hline
\end{tabular}

Note: Column percentage. Age group cross tabulation. $\mathrm{N}=200$

The respondents were afterwards asked to specify which services they utilize to keep in touch with their friends and families. There were five possible answers: calls, SMS, Facebook Messenger, Skype and Whatsapp. By analyzing the responses, two different trends can be delineated: to communicate with their friends, they tend to mainly use the Whatsapp app (95\% of respondents) and, to a lesser extent, calls (73\%). Conversely, to keep in touch with their families, they mostly use calls (98\%) and SMS (48\%). Skype use is quite marginal (only 10\% of the sample uses it to keep in touch with friends and 3\% to communicate with family members). Spurious digital natives tend to prefer traditional services: calls and text messages, while pure digital natives are more likely to use applications based on instant messaging: Facebook Messenger and WhatsApp.

In addition to calls and messaging, pure natives are more likely to use their smartphones for applications and video games, while early adults are more inclined to check e-mails, bank accounts, and work-related matters, as well as booking travel reservations and purchasing items online (Chart 1). Pure digital natives express a greater fear that their cell phone battery might run low. When asked, "Do you ever fear that your cell phone might run out of power?" $23 \%$ answered "often" (versus 12\% of spurious digital natives) and 51\% replied "sometimes" (versus 44\% of spurious digital natives). $28 \%$ of young adults also claim never to contact a person without using a mobile phone, compared to $11 \%$ of early adults.

This tendency of pure digital natives towards greater and more constant use of their smartphones was confirmed in a series of dichotomous questions. Pure digital natives tend to keep their phones switched on during the night more often than spurious natives ( $81 \%$ versus $70 \%)$, to check their phone as soon as they get up in the morning $(68 \%$ versus $49 \%$ ), to post pictures or comments regarding places they have visited for the first time (43\% versus $41 \%)$, and to check the time on their phone, rather than on a wristwatch $(69 \%$ versus $64 \%)$.

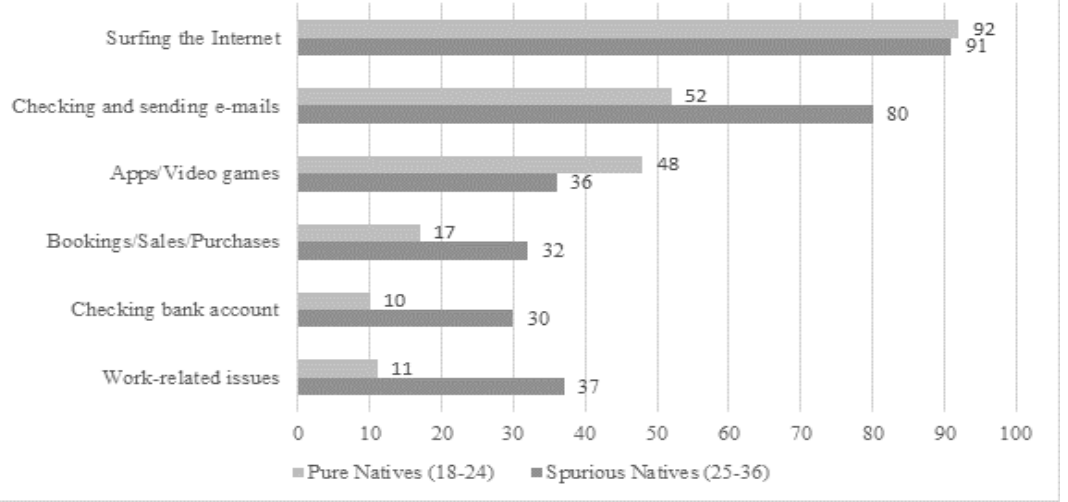

Figure 1. Smartphone use in addition to calls and messaging 
Furthermore, more often than early adults, they state that spending a whole day without their mobile phone would be a strongly negative occurrence (43\% versus 35\%). Pure digital natives also believe that smartphones, the Internet, and social networks have significantly improved their social life (54\% versus 40\%) and they find it impossible to imagine their future life without a smartphone (63\% versus $52 \%)$.

The successive part of the questionnaire displayed four common circumstances: waiting situations (on the bus, in a waiting room, etc.), in the car at a red traffic light, walking, and spending time with other people. Respondents were asked to indicate during which activities they make use of their phones. As can be seen from Chart 2, there are no particular differences between the two age groups. However, for both age classes, it is interesting to note the high percentage of affirmative responses.

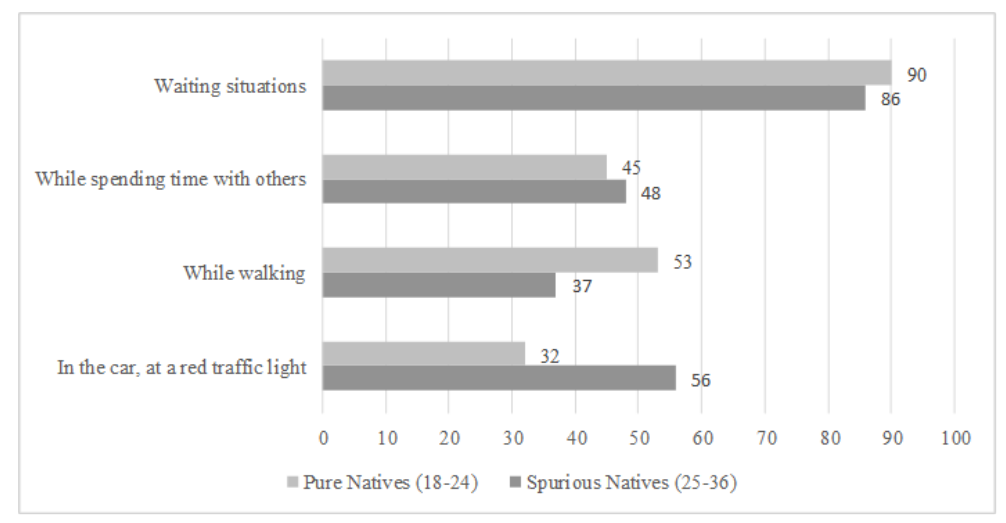

Figure 2. Smartphone usage in recurring situations

The last question of the questionnaire was open-ended and asked the respondents to imagine and specify their own personal feelings in the event of being prevented from using their smartphones. The analysis and processing of the responses resulted in four main categories (Table 3). By crossing such categories with age class, some significant differences can be seen; pure digital natives are more inclined towards anxiety and frustration, while spurious ones greatly associate the separation from their phones with diametrically opposing feelings: tranquility, relaxation and an overall sense of freedom.

Table 3. Experienced feelings in the case of forced smartphone absence

\begin{tabular}{|l|c|c|c|}
\hline \multirow{2}{*}{} & \multicolumn{2}{|c|}{ Age } & Total \\
\cline { 2 - 4 } & $\begin{array}{c}\text { Pure Natives } \\
(\mathbf{1 8 - 2 4})\end{array}$ & $\begin{array}{c}\text { Spurious Natives } \\
(\mathbf{2 5 - 3 6 )}\end{array}$ & $33.0 \%$ \\
\hline Anxiety/Frustration & $38.0 \%$ & $28.0 \%$ & $43.0 \%$ \\
\hline Sense of freedom & $24.0 \%$ & $42.0 \%$ & $23.0 \%$ \\
\hline Fear of being unreachable & $22.0 \%$ & $24.0 \%$ & $3.0 \%$ \\
\hline Work-related fears & $6.0 \%$ & -- & $8.0 \%$ \\
\hline Other feelings & $10.0 \%$ & $6.0 \%$ & $100.0 \%$ \\
\hline Total & $100.0 \%$ & $100.0 \%$ & \\
\hline
\end{tabular}

Note: Column percentage. Age group cross tabulation. $\mathrm{N}=200$

\section{Final Considerations}

The survey results exposed in this essay display a clear trend; almost every question of the questionnaire has shown significantly different leanings between the two generational cohorts. The assumptions made at the beginning, 
forming the study's initial hypotheses, have been substantiated by this preliminary study in Italy. Pure digital natives show a stronger bond to their smartphones, which can be seen as both an emotional attachment and a true dependence. Behavior that might indicate a greater predisposition to nomophobia is seen to a greater extent in the pure digital cohorts. In this study, such a trend has been observed in a sample of Italian respondents and therefore must be circumscribed to the Italian scenario. However, it seems safe to assume similar trends in virtually every country with a high rate of smartphone penetration.

At this point, there is another legitimate "public health" question to be asked: should nomophobia be considered a disease in the full sense of the term? The studies on this subject are currently scarce, particularly those with a purely medical focus. According to David Greenfield, a professor of psychiatry at the University of Connecticut, the attachment to smartphones is very similar to other well-known and well-researched dependencies, because - in a similar way - it interferes with the production of dopamine, a neurotransmitter that regulates the brain's reward center. As stated by Greenfield in a recent interview:

\begin{abstract}
Every time you get a notification from your phone, there's a little elevation in dopamine that says you might have something that's compelling, whether that's a text message from someone you like, an email, or anything. [...] The thing is you don't know what it's going to be or when you're going to get it, and that's what compels the brain to keep checking. [...]. That feeling you're going to miss something if you're not constantly checking is an illusion; most parts of our lives are not relevant to our smartphones (Stone, 2014).
\end{abstract}

Nicola Luigi Bragazzi and Giovanni Del Puente, two researchers at the University of Genoa - who also proposed the inclusion of nomophobia in the Diagnostic and Statistical Manual of Mental Disorders - have connected the nomophobia phenomenon to the new technologies paradox, describing it as a two-faced phobia: on the one hand, the smartphone can be used in an impulsive way as a protective shield; on the other hand, it can be used as a means for avoiding social communication (Billieux, Van der Linden \& Rochat, 2008; Ribak, 2009; Bragazzi \& Del Puente, 2014). According to these scholars,

It is undeniable that technology [...] enables us to perform our job more quickly and with efficiency. [...] On the other hand, mobile devices can have a dangerous impact on human health. Further research is needed, above all academic and scholarly studies, to investigate more in depth the psychological aspects of nomophobia and to provide a standardized and operational definition of it (Bragazzi \& Del Puente, 2014, p. 158).

Smartphone addiction is being considered by some researchers as new clinical condition worthy of further research. The academic world is showing how, currently, being disconnected from a phone or a computer can cause anxiety, discomfort, irritability, stress and panic (King, Valença \& Nardi, 2010; Bivin, Preeti, Praveen \& Jinto, 2013; King et al., 2014; Kang \& Jung, 2014) - negative emotions that are disproportionate to the real situation of personal danger, and therefore pathological. Certainly not all behaviors related to the use of smartphones can be defined as pathological, but it is undeniable that today's massive diffusion of smartphones - particularly among the youngest generations - has resulted in the emergence of a new hazardous phenomenon that requires further research.

In conclusion, two variables, in the judgment of this researcher, should no longer be ignored: generational belonging and, most importantly, digital nativity. Their importance is evidenced by the fact that, as shown in this brief research note, nomophobia is certainly stronger among those born and raised during the technology boom at the dawn of this new millennium.

\title{
References
}

Allega, A. M. (2013). Lo Tsunami dei Nativi Digitali. Gli Speciali di Education 2.0, 1(1), 9-10.

Billieux, J., Van der Linden, M. \& Rochat, L. (2008). The Role of Impulsivity in Actual and Problematic Use of the Mobile Phone. Applied Cognitive Psychology , 22(9), 1195-1210. doi:10.1002/acp.1429.
Bivin, J. B., Preeti, M., Praveen, C. T. \& Jinto, P. (2013). Nomophobia: Do We Really Need to Worry About? Reviews of Progress, 1(1), 1-5.

Bragazzi, N. L. \& Del Puente, G. (2014). A Proposal for Including Nomophobia in the New DSM-V, Psychology Research and Behavior Management, 7, 155-160. 
Colleen, L. (2008, March 3). Nomophobia: "No More Phobia”. Siude, Retrieved from http://web.archive.org/ web/20080405161056/http://media.www.siude.com/media/ storage/paper1096/news/2008/04/03/Columns/Column. Nomophobia.no.More.Phobia-3299034.shtml.

Cristofori, C., Bernardini, J. \& Massarini, S. (2015). Giovani nella Rete della Politica. Un'Indagine in Facebook. Milan: FrancoAngeli.

D’Agata, C. (2008, April 3). Nomophobia: Fear of Being Without Your Cell Phone. CBS News, Retrieved from http://web. archive.org/web/20080412042610/http://www.wsbt.com/ news/health/17263604.html.

Ferri, P. (2011), Nativi Digitali. Turin: Bruno Mondadori.

Ferri, P. (2013). La Sfida dei Nativi Digitali. Gli Speciali di Education 2.0, 1(1), 3-4.

Harris Interactive (2012). Mobile Mindset Study. Retrived from https://www.mediaenmaatschappij.nl/images/artikelen/PDF/ Mobile\%20Mindset,\%20Juni\%202012.pdf

Jayakumar, A. (2008, April 3). Break Free from Nomophobia, Drunkorexia. Mid-Day, Retrived from http://web. archive.org/web/20080404075714/http://www. mid-day.com/web/guest/lifeatwork/lifeatwork/ article?_EXT_5_articleId=1071008\&_EXT_5_groupId=14.

Kang, S. \& Jung, J. (2014). Mobile Communication for Human Needs: A Comparison of Smartphone Use Between the US and Korea. Computers in Human Behavior, 35, 376-387. doi: 0.1016/j.chb.2014.03.024, Retrived from https://www.sciencedirect.com/science/article/pii/S0747563214001460

Kemp, S. (2018). Digital in 2015. Essential Insights into Internet, Social Media, Mobile, and E-commerce use around the world, We Are Social, Retrieved from https://wearesocial.com/ blog/2018/01/global-digital-report-2018.
King, A. L. S., Valença, A. M. \& Nardi, A. E. (2010). Nomophobia: The Mobile Phone in Panic Disorder with Agoraphobia: Reducing Phobias or Worsening of Dependence? Cognitive and Behavioral Neurology, 23(1), 52-54.

King, A. L. S, Valença, A. M., Silva, A. C., Sancassiani, F., Machado, S. \& Nardi, A. E. (2014). "Nomophobia": Impact of Cell Phone Use Interfering with Symptoms and Emotions of Individuals with Panic Disorder Compared with a Control Group. Clinical Practice \& Epidemiology in Mental Health , 10(1), 28-35. 10.2174/1745017901410010028.

Prensky, M. (2001). Digital Natives, Digital Immigrants. On the Horizon, 9(5), 1-6, Retrieved from https://www.marcprensky.com/writing/Prensky\%20-\%20Digital\%20Natives,\%20 Digital\%20Immigrants\%20-\%20Part1.pdf

Prensky, M. (2012). Brain Gain. Technology and the Quest for Digital Wisdom. London: Palgrave Macmillan.

Ribak, R. (2009, March 27). Remote Control, Umbilical Cord and Beyond: The Mobile Phone as a Transitional Object. British Journal of Developmental Psychology, 27(1), 183-196, Retrieved from https://www.ncbi.nlm.nih.gov/ pubmed/19972668

Stone, M. (2014, July 31). Smartphone Addiction Now Has a Clinical Name. Business Insider Retrieved from http://www. businessinsider.com/what-is-nomophobia-2014-7?IR=T. 